\title{
Endodontic Management of External Replacement Resorption
}

\author{
Harshita Gwalani ${ }^{1}$, Akansha Jharwal $^{2}$, Deepak Raisingani ${ }^{3}$, Ashwini Prasad $^{4}$, Harshit Srivastava $^{5}$, Prachi Mital ${ }^{6}$
}

\begin{abstract}
Tooth resorption results from injuries to or irritation of the periodontal ligament and/or pulp. It may arise as a sequalae of traumatic luxation injuries, orthodontic tooth movement, or chronic infections of the pulp or periodontal structures. In extensive traumatic injuries, healing does not take place by the adjacent vital cells and the bone can establish a contact with the root surface, making the tooth an essential part of the bone remodelling system. This phenomenon is termed as dento-alveolar ankylosis. Resorption can occur without any further stimulation and this activity involves osteoclastic resorption dependent on parathyroid-hormone-generated resorption and bacterial invasion. Such teeth elicit a high metallic sound on percussion; on continuous resorptive attacks, the teeth become infra-occluded. Successful management of resorption cannot always be a predicted. However, an experimental approach to manage the initial stage of inflammatory response is to decrease the formation of clastic cells, and to induce repair of damaged root surfaces by cementoblasts. The purpose of this case report wass to review this entity, to discuss factors that influence the occurrence of resorption, and to describe appropriate treatment. A case of external replacement resorption is presented, illustrating previous root canal therapy. After a meticulous diagnosis, a stringent treatment plan was executed. A nonsurgical endodontic therapy was performed with the use of calcium hydroxide as an intracanal medicament. $2 \%$ chlorhexidine was used as a final irrigant. A 3-months followup radiograph revealed adequate control of replacement resorption and the tooth was obturated. Subsequent followup showed a perceptible halt in the dento-alveolar ankylosis.

Keywords: Ankylosis, Calcium hydroxide, Chlorhexidine, Replacement resorption.

Journal of Mahatma Gandhi University of Medical Sciences \& Technology (2018): 10.5005/jp-journals-10057-0078
\end{abstract}

\section{INTRODUCTION}

Absence of evidence is not evidence of absence. In other words, what we do not see does not mean it does not exist. "First, do not harm." As clinicians, we must preserve this goal in all our treatments, but even in the best of hands, and with every positive intention, this is not always possible. Tooth resorption is one such vexatious dental condition in which the body's own cells eat away and dissolve tooth structure. Simply put, for adults, tooth resorption is an uncommon problem; however, in growing children, resorption is the natural process that causes the roots of primary teeth to be removed, facilitating their replacement with permanent teeth. Tooth resorption is a condition identified as a physiologic or a pathologic process that results in loss of dentin, cementum, or bone. ${ }^{1}$ Tooth resorption involves an elaborate interaction among inflammatory cells, resorbing cells, and hard tissue structures. Frequently, this pathologic condition is difficult to predict, diagnose, and treat. ${ }^{2}$ The etiology of tooth resorption involves injury to non-mineralized tissues on the external surface (pre-cementum) or the internal surface (pre-dentin) of the root. ${ }^{3}$ Various classifications of resorption have been based on etiology, site, morphology, or a combination of these three factors. ${ }^{4}$

According to American Association of Endodontists, tooth resorption can be classified as follows:

- Internal resorption

- Root canal replacement resorption

Internal inflammatory resorption

- External root resorption

- Surface resorption

Inflammatory resorption

Replacement resorption

Dento-alveolar resorption

- Pathologic root resorption

Biological mechanisms involving osteoprotegerin (OPG), receptor activator of nuclear factor kappa-B ligand (RANKL), receptor
${ }^{1-6}$ Department of Conservative Dentistry and Endodontics, Mahatma Gandhi Dental College and Hospital, Mahatma Gandhi University of Medical Sciences and Technology, Jaipur, Rajasthan, India

Corresponding Author: Harshita Gwalani, Department of Conservative Dentistry and Endodontics, Mahatma Gandhi Dental College and Hospital, Mahatma Gandhi University of Medical Sciences and Technology, Jaipur, Rajasthan, India, Phone: +91 7597924182, e-mail: dr.harshitagwalani@gmail.com

How to cite this article: Gwalani $H$, Jharwal A, Raisingani $D$, et al. Endodontic Management of External Replacement Resorption. J Mahatma Gandhi Univ Med Sci Tech 2018;3(2):73-77.

Source of support: Nil

Conflict of interest: None

activator of nuclear factor kappa B, substance P, NKA, NPY, VIP, and CGRP play an imperative role through their vasoactive, chemotactic, and cellular effects. ${ }^{5}$ Risk factors in patients involve a past history of resorption, decay, roots with developmental abnormalities, a past history of trauma, patient age, chronic alcoholism, genetic factors, systemic causes (respiratory disorders, drugs, nutritional and hormonal deficits, hypopituitarism, and hypothyroidism), toothrelated factors (dimensions of tooth, expanding pathological lesions, tooth impactions, root proximity, alveolar bone density, endodontic treatment, severity and type of malocclusion, increased probing depths, and reduced crestal bone height). ${ }^{6,7}$ Risk factors related to management involve high masticatory forces, orthodontic tooth movement, high temperatures, and iatrogenic trauma to the roots. The fundamentals of managing a resorption is to cease the action of clastic cells; the same can be achieved by eliminating the cause of stimulation, osteoclastic function, and enhancement of repair.

\section{Case Description}

An 18-year-old male reported to the Department of Conservative Dentistry and Endodontics, Mahatma Gandhi Dental College and

(c) The Author(s). 2018Open Access This article is distributed under the terms of the Creative Commons Attribution 4.0 International License (https://creativecommons. org/licenses/by-nc/4.0/), which permits unrestricted use, distribution, and non-commercial reproduction in any medium, provided you give appropriate credit to the original author(s) and the source, provide a link to the Creative Commons license, and indicate if changes were made. The Creative Commons Public Domain Dedication waiver (http://creativecommons.org/publicdomain/zero/1.0/) applies to the data made available in this article, unless otherwise stated. 
Hospital with a chief complaint of food lodgement in the lower right back tooth region (Fig. 1). The patient gave a history of previous root canal therapy completed 3 years ago without a coronal prosthesis.

Clinical examination revealed dislodged temporary restoration with a disto-proximal carious lesion (Fig. 2). Percussion test elicited a high-pitched metallic sound. Radiographic evaluation revealed an extensive damage to the periodontal ligament space on the distal root; radiographs were shot at straight, mesial, and distal angulation for a definitive diagnosis (Figs 3 and 4). Distal root on a straight angulation depicted a massive loss of PDL space with a predominant healing response from the bony socket wall, with the root structure gradually being replaced by bone. Definitive diagnosis of external replacement resorption on the distal root of 46 was established. Tooth was isolated, access cavity was slightly modified using Endo Access Kit (Dentsply), and root filling was removed from the distal root canal system under $2.5 \times$ magnification (Fig. 5). Working length was determined using electronic apex locator (Propex II Dentsply) and confirmed radiographically. Cleaning and shaping was performed using HyFlex CM (Coltene) \#25 (6\%). Copious irrigation was performed using $5 \% \mathrm{NaOCl}$ (Prime Dental) and 17\% EDTA (META MD) (Dentsply Glyde). 2\% chlorhexidine was used as the final rinse. Calcium hydroxide with iodoform (Meta Biomed Metapex) was used as an intracanal medicament to halt the process of

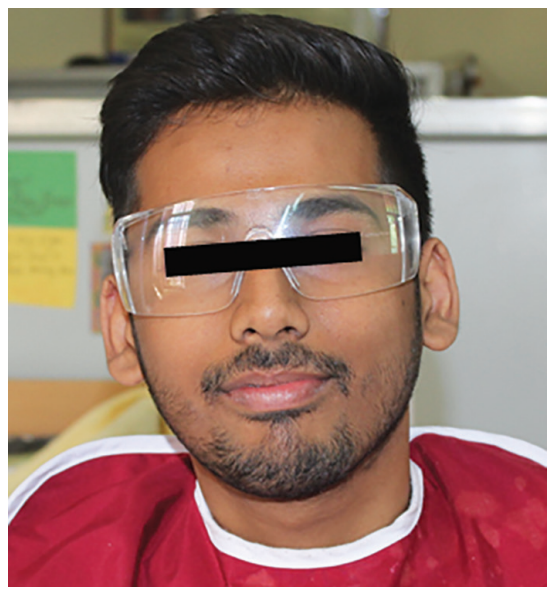

Fig. 1: 18-year-old patient

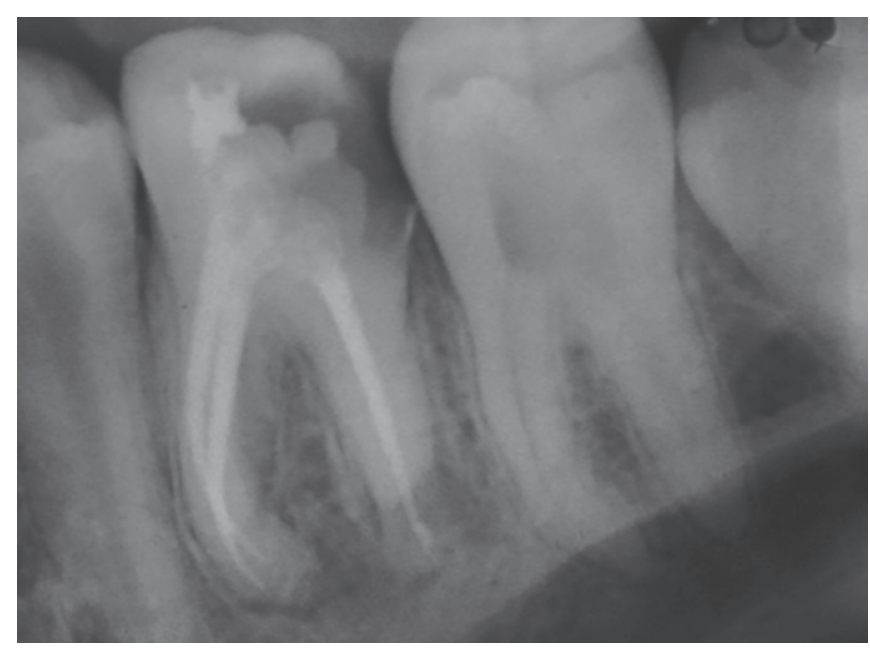

Fig. 3: Preoperative radiograph resorption (Fig. 6). One month later patient returned, the tooth was radiographically evaluated for repair, and old dressing was removed with the help of hedstrom files and normal saline. Distal root canal system was again packed with metapex dressing; temporization at all sittings was done using zinc phosphate cement (Figs 7 and 8). Two months of calcium hydroxide dressing revealed considerable repair of the periradicular attachment (Fig. 9). The tooth was thoroughly irrigated using saline and $2 \%$ chlorhexidine flush, metapex dressing was replaced, and the tooth was temporized. Three months of stringent calcium hydroxide therapy revealed appreciable control of replacement resorption. Obturation was accomplished with the lateral compaction technique using gutta percha points (Dentsply) and AH Plus resin sealer (Dentsply) (Figs 10 and 11). A 6-months followup shows complete healing of the distal root canal system (Figs 12 and 13).

\section{Discussion}

Root resorption is a PDL complication that represents injury to the cementum. When compared to the bone (which has a continuous physiologic remodeling), the process of resorption is invariably inflammatory in nature. Therefore, resorption in the permanent teeth is considered as a pathologic event, and if left untreated, may

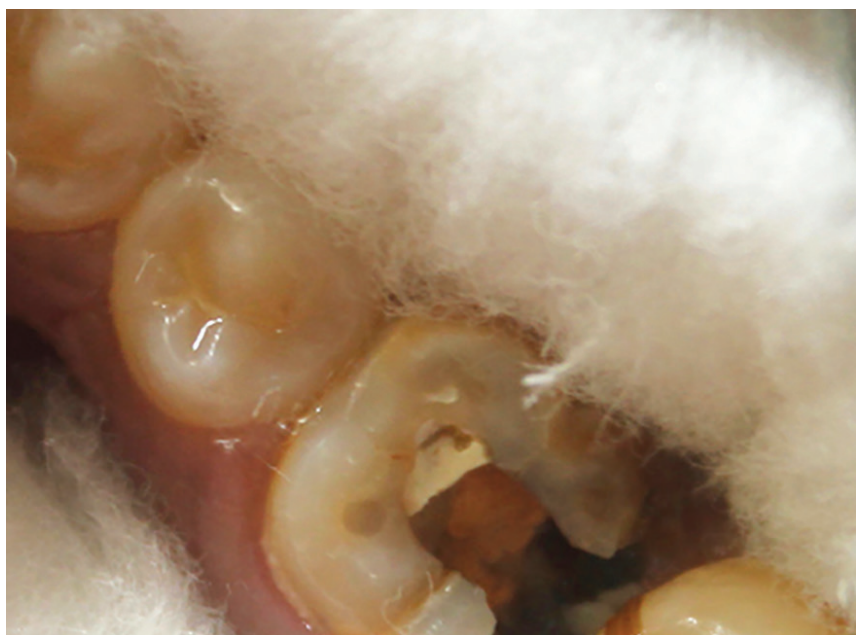

Fig. 2: Clinical view

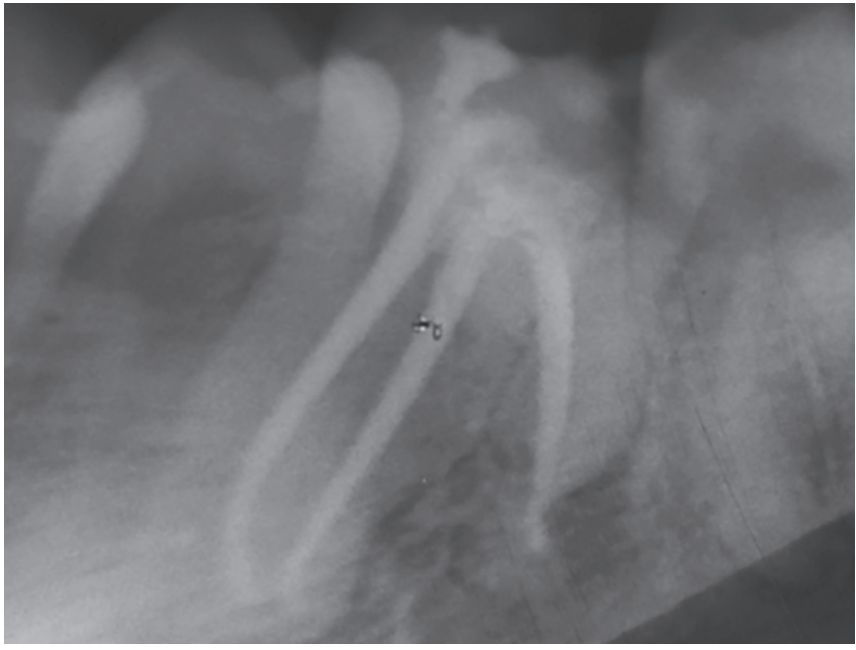

Fig. 4: Preoperative radiograph at distal angulation 


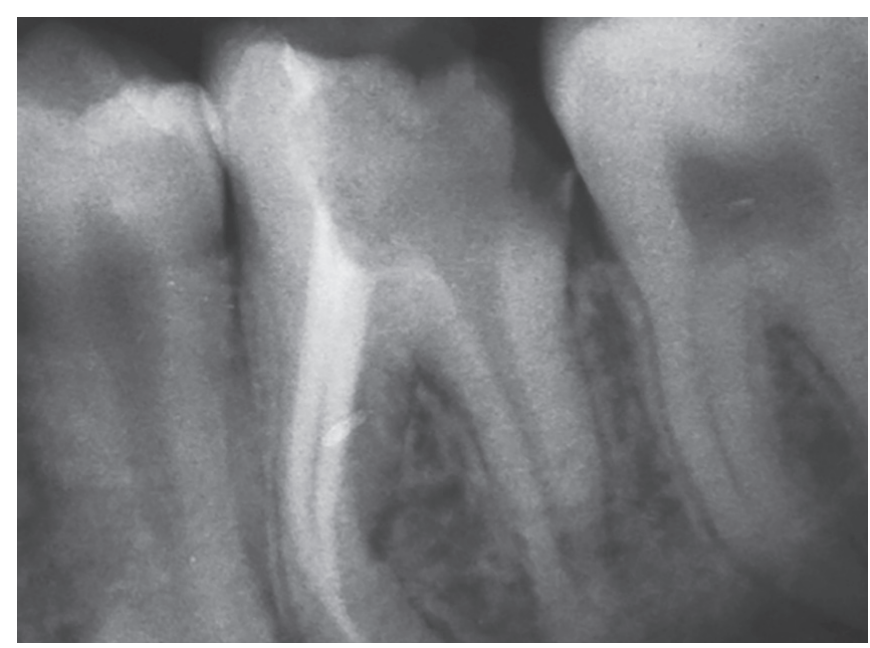

Fig. 5: Root filling retrieved

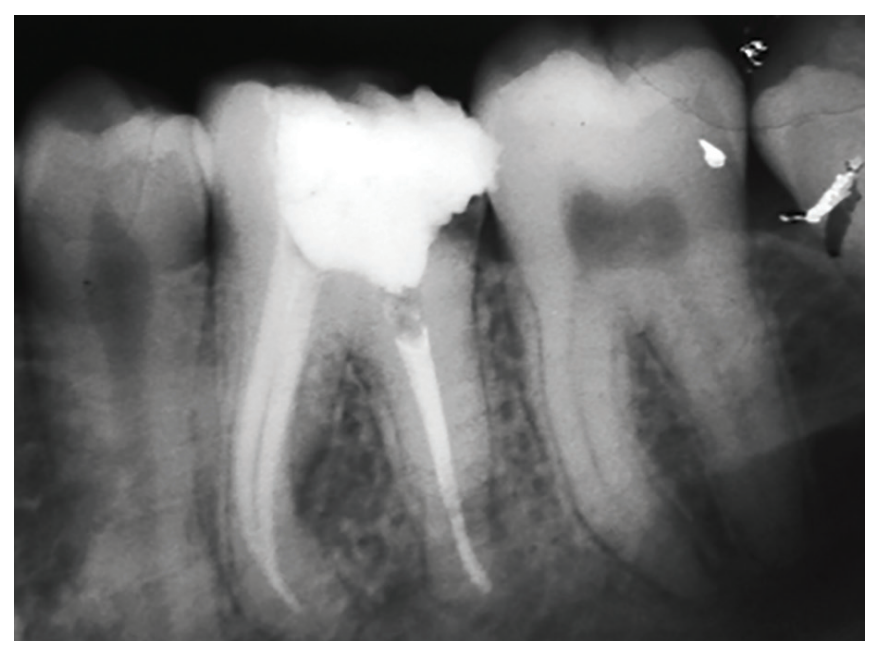

Fig. 7: Metapex dressing (replaced)

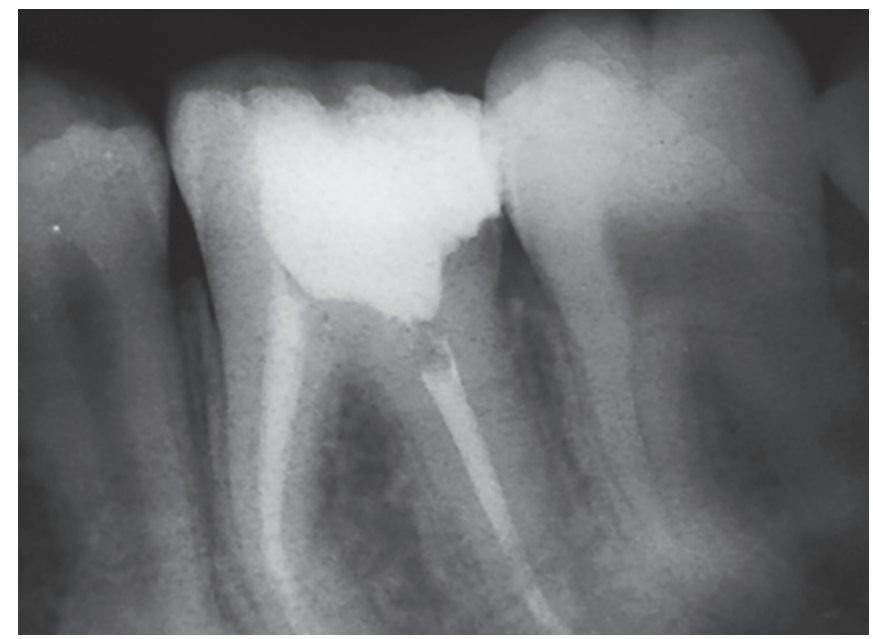

Fig. 9: Repair after 2 months

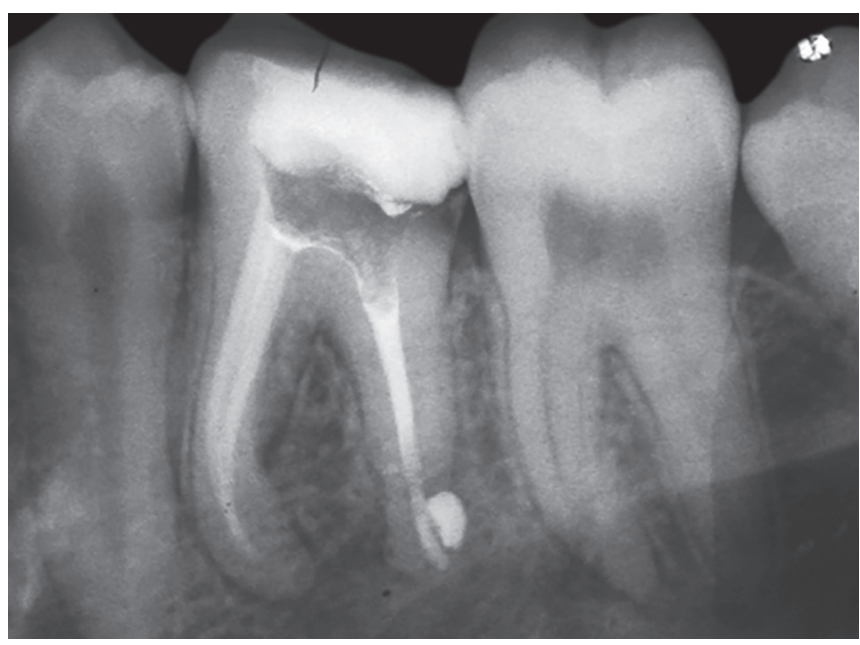

Fig. 6: Metapex dressing placed (1 month)

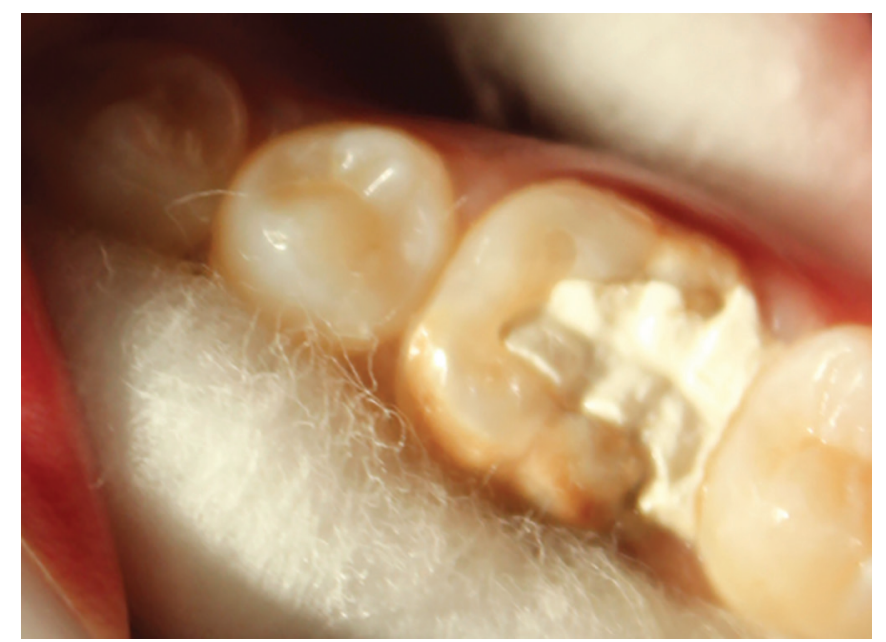

Fig. 8: Temporization

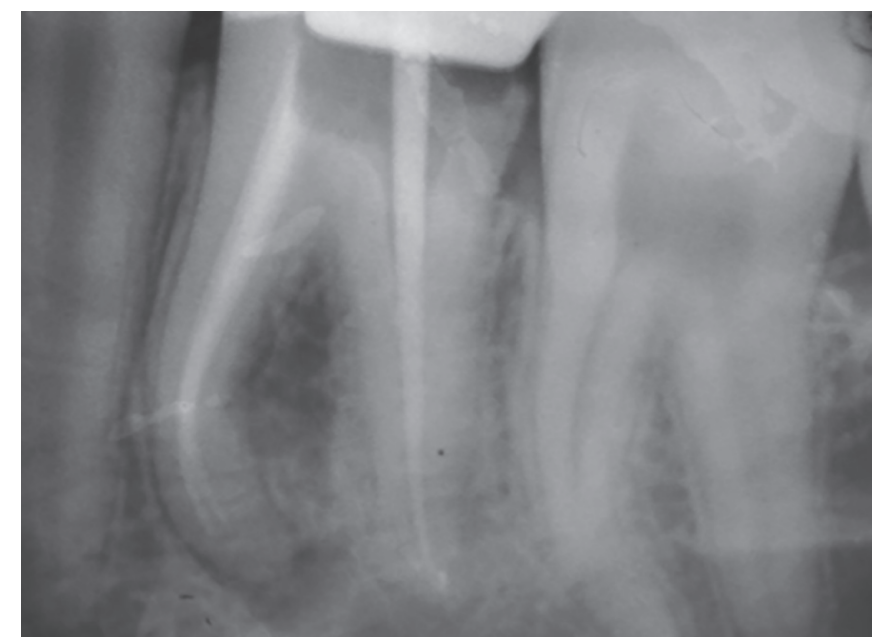

Fig. 10: Master cone 


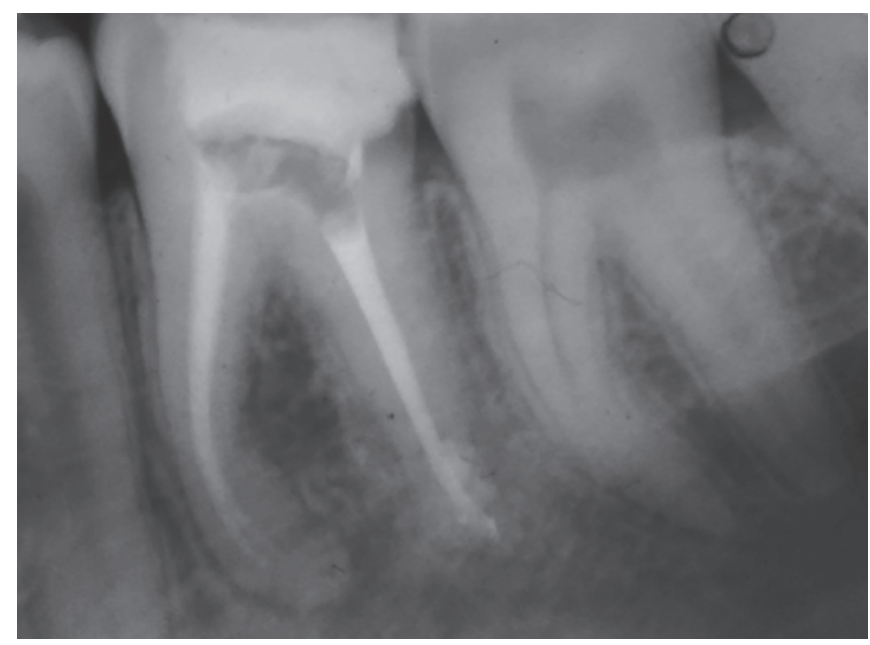

Fig. 11: Obturation

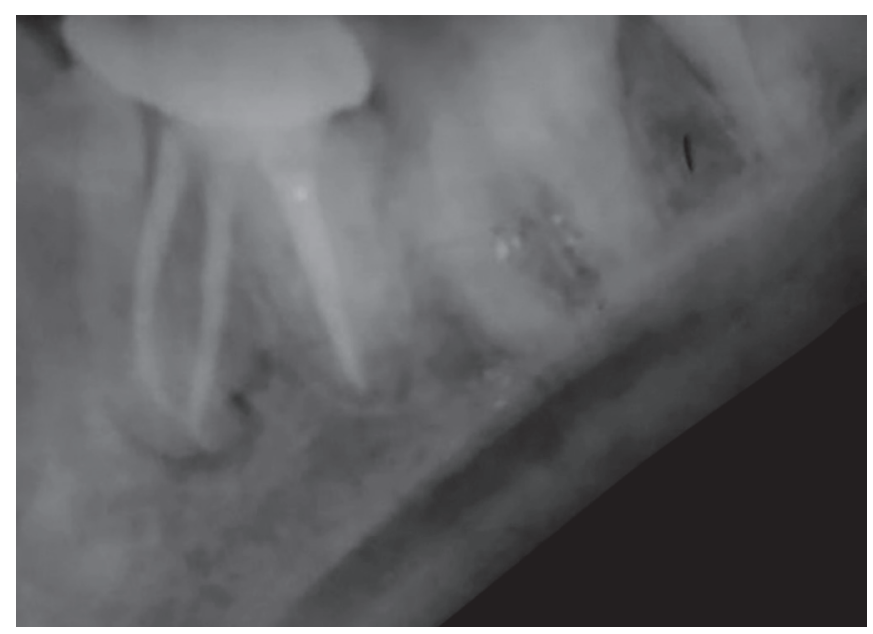

Fig. 13: Six months follow-up at distal angulation

result in the premature loss of the tooth. The mineralized tissues of permanent teeth are not normally resorbed. They are protected in the root canal by the pre-dentin and the odontoblasts and on the root surface by the pre-cementum and the cementoblasts. If the pre-dentin or pre-cementum becomes mineralized or, in the case of the pre-cementum, is mechanically damaged or scrapped off, multinucleated cells will colonize the mineralized or denuded surfaces and resorption will ensue. Not only development but also the presence of the alveolar bone depends on the presence of cementum. ${ }^{8}$ If for any cause (inflammation, trauma, senescence) the cementum becomes resorbed, the adjacent alveolar bone is resorbed, owing to the lack of functional stimulus. If the cementum is resorbed, the fibers of the periodontal membrane lose their attachment to the tooth. The stimulus of the function cannot be transmitted to the surrounding tissue, and so the alveolar bone becomes resorbed. The cementum is resorbed, and the osteoblasts occupy the resorption lacunae. The principal fibers of the periodontal membrane disappear, and soft tissue occupies their place. The fibers are not stretched but they run in every direction. The alveolar bone lying opposite to the resorbed cementum is also resorbed. The damage done by resorption is irreparable. Etiology of resorption includes:

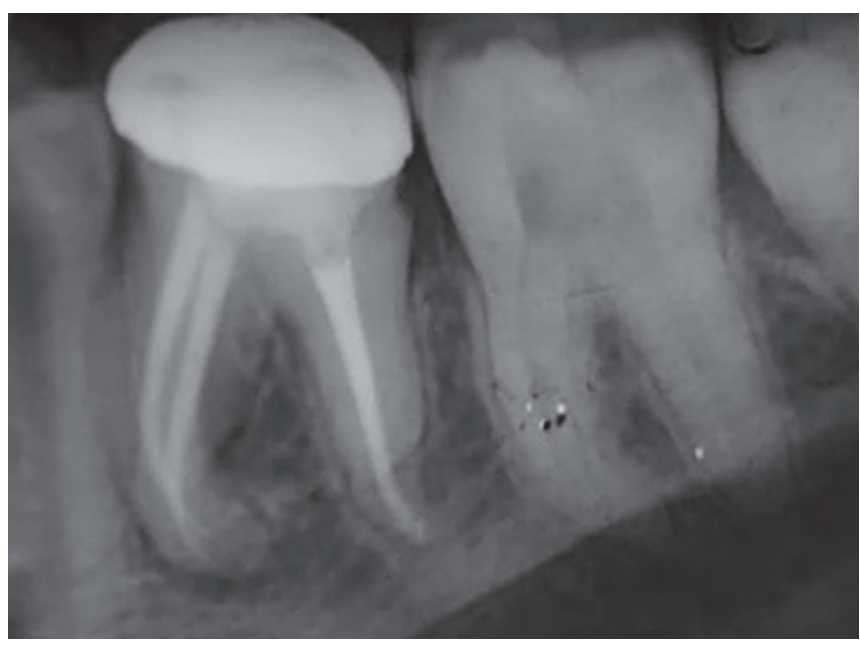

Fig. 12: Six months follow-up

- Injury

- Stimulation

Injury occurs to the non-mineralized tissues, pre-cementum or predentin ${ }^{9}$ during mechanical trauma, surgical procedures, excessive pressure of an impacted tooth or tumor, and/or chemical irritation during bleaching procedures. However, if the process is not further stimulated, the process ceases spontaneously. If the defect is not large, repair can occur with cementum-like tissue. However, if the defect is large, bone cells are able to attach to the root surface before the cementum-producing cells, resulting in ankylosis. Osteolclastic cells are responsible for active resorption. The origin of osteolclastic activity is different for each type of resorption; hence, the stimulating factors should be identified before management. Various causes of resorption include lateral luxations, intrusions, and replantation of the avulsed tooth. There is a loss of homeostasis in PDL; therefore, healing takes place from adjacent healthy PDL. However, if the healing occurs from bony alveolus, it forms a bony bridge between socket wall and root surface. Healing events from the bony alveolus result in the creation of a bony bridge between the socket wall and the root surface. In moderate-sized injuries (1-4 $\mathrm{mm}^{2}$ ), initial ankylosis is formed. Under functional mobility, a nonrigid splint or without splinting, these small areas of resorption replace new cementum and PDL attachment, such a resorption is known as transient ankylosis. In cases of more extensive injuries $\left(>4 \mathrm{~mm}^{2}\right)$, a progressive ankylosis occurs. ${ }^{10}$ In progressive ankylosis, tooth is an integral part of bone remodelling system. Such an ankylosis is very active in young patients and result in gradual infra-occlusion and loss of the offending tooth within 1-5 years. Replacement resorption is considerably slow in older patients, offending tooth can function for 5-20 years, and the tooth acts similar to an implant. The rationale of managing resorption is to eliminate bacteria in root canal and dentinal tubules and accelerate healing in the periradicular space (root surface, $\mathrm{PDL}$, and adjacent alveolar bone). $\mathrm{Ca}(\mathrm{OH})_{2}$ serves well as an intracanal medicament as it counteracts surviving bacteria and inhibits the process of resorption. Nevertheless, the dentin that is lost through resorption cannot be replaced and healing occurs by formation of a cementum or bone. When resorptive lesion is arrested, replacement occurs by formation of either cementum or bone whichever cells are active adjacent to the resorptive lesion. 
Successful healing of $88 \%$ have been reported in two clinical studies.

\section{Conclusion}

Identifying the stimulant and removing the etiological factors are of utmost importance for promoting repair. This case report describes a transient replacement resorption that can help the clinician in prompt diagnosis, elimination, and management of this pathological entity.

\section{References}

1. Ne RF, Witherspoon DE, Gutmann J. Tooth resorption. Quintessence Int 1999;30:9-25.

2. Tronstad L. Root resorption - etiology, terminology and clinical manifestations. Endod Dent Traumatol 1988;4:241-252.

3. Trope M. Root resorption of dental and traumatic origin: classification based on etiology. Pract Periodont Aesthet Dent 1998;10:515-522.
4. Discacciati JA, de Souza EL, Costa SC, et al. Invasive cervical resorption: etiology, diagnosis, classification and treatment. J Contemp Dent Pract 2012 Sep;13:723-728.

5. Kanzaki H, Chiba M, Shimizu Y, et al. Dual regulation of osteoclast differentiation by periodontal ligament cells through RANKL stimulation and OPG inhibition. J Dent Res 2001;80:887-891. DOI: 10.1177/00220345010800030801.

6. Darcey J, Qualtrough A. Resorption: part 1. Pathology, classification and aetiology. Br Dent J 2013;214:439-451. DOI: 10.1038/sj.bdj.2013.431.

7. Sameshima GT, Sinclair PM. Predicting and preventing root resorption: Part I. Diagnostic factors. Am J Orthod Dentofacial Orthop 2001 May;119(5):505-510. DOI: 10.1067/mod.2001.113409.

8. Balint $O$. Resorption and repair on the surface of the root. JADA Sept 1928;15(9):1768-1777. DOI: 10.14219/jada.archive.1928.0300.

9. Andreasen JO, Hjorting-Hnasen E. Replantation of teeth. Part I. Radiographic and clinical study of 110 human teeth replanted after accidental loss. Acta Odontol Scand 1966;24:263-286. DOI: 10.3109/00016356609028222.

10. Andersson L, Lindskog S, Blomlo TL. Effect of masticatory stimulation on dentoalveolar ankylosis after experimental tooth replantation. Endod Dent Traumatol 1985;1(1):13-16. 